\title{
Predicting readmission to intensive care after cardiac surgery within index hospitalization: A systematic review
}

DOI:

10.1053/j.jvca.2021.02.056

\section{Document Version}

Accepted author manuscript

Link to publication record in Manchester Research Explorer

\section{Citation for published version (APA):}

Kimani, M. L., Howitt, D. S., Tennyson, M. C., Templeton, D. R., McCollum, P. C., \& Grant, M. S. W. (2021). Predicting readmission to intensive care after cardiac surgery within index hospitalization: A systematic review. Journal of Cardiothoracic and Vascular Anesthesia. https://doi.org/10.1053/j.jvca.2021.02.056

\section{Published in:}

Journal of Cardiothoracic and Vascular Anesthesia

\section{Citing this paper}

Please note that where the full-text provided on Manchester Research Explorer is the Author Accepted Manuscript or Proof version this may differ from the final Published version. If citing, it is advised that you check and use the publisher's definitive version.

\section{General rights}

Copyright and moral rights for the publications made accessible in the Research Explorer are retained by the authors and/or other copyright owners and it is a condition of accessing publications that users recognise and abide by the legal requirements associated with these rights.

\section{Takedown policy}

If you believe that this document breaches copyright please refer to the University of Manchester's Takedown Procedures [http://man.ac.uk/04Y6Bo] or contact uml.scholarlycommunications@manchester.ac.uk providing relevant details, so we can investigate your claim.

\section{OPEN ACCESS}




\section{Journal of Cardiothoracic and Vascular Anesthesia Predicting readmission to intensive care after cardiac surgery within index hospitalization: A systematic review \\ --Manuscript Draft--}

\begin{tabular}{|c|c|}
\hline Manuscript Number: & JCVA-D-20-00378R2 \\
\hline Article Type: & Review Article \\
\hline Keywords: & cardiac surgery; Readmission intensive care; risk prediction model \\
\hline Corresponding Author: & $\begin{array}{l}\text { Linda Kimani, MBBS, MRCS } \\
\text { The University of Manchester } \\
\text { Manchester, UNITED KINGDOM }\end{array}$ \\
\hline First Author: & Linda Kimani, MBBS, MRCS \\
\hline \multirow[t]{6}{*}{ Order of Authors: } & Linda Kimani, MBBS, MRCS \\
\hline & Samuel Howitt, PhD, FRCA \\
\hline & Charlene Tennyson, MBBS, MRCS \\
\hline & Richard Templeton, FRCA, FFICM \\
\hline & Charles McCollum, MD, FRCS \\
\hline & Stuart W. Grant, PhD, FRCS(cth) \\
\hline Abstract: & $\begin{array}{l}\text { Readmission to the cardiac intensive care unit (CICU) after cardiac surgery has } \\
\text { significant implications for both patients and healthcare providers. Identifying patients } \\
\text { art risk of readmission could potentially improve outcomes. The objective of this } \\
\text { systematic review was to identify risk factors and clinical prediction models for } \\
\text { readmission within a single hospitalization to intensive care after cardiac surgery. } \\
\text { PubMed, MEDLINE and EMBASE databases were searched to identify candidate } \\
\text { articles. Only studies that utilised multivariable analyses to identify independent } \\
\text { predictors were included. } \\
\text { There were } 25 \text { studies and five risk prediction models identified. The overall rate of } \\
\text { readmission pooled across the included studies was } 4.9 \% \text {. In all } 25 \text { studies, in-hospital } \\
\text { mortality and duration of hospital stay were higher in patients who experienced } \\
\text { readmission. Recurring predictors for readmission were; preoperative renal failure, age } \\
\text { >70, diabetes, chronic obstructive pulmonary disease, preoperative left ventricular } \\
\text { ejection fraction <30\%, type and urgency of surgery, prolonged cardiopulmonary } \\
\text { bypass time, prolonged post-operative ventilation, postoperative anaemia and } \\
\text { neurological dysfunction. The majority of readmissions occurred due to respiratory and } \\
\text { cardiac complications. Four models were identified for predicting readmission, with one } \\
\text { external validation study. As all models developed to date have limitations, further work } \\
\text { on larger datasets is required to develop clinically useful models to identify patients at } \\
\text { risk of readmission to CICU after cardiac surgery. }\end{array}$ \\
\hline
\end{tabular}


Tuesday $31^{\text {st }}$ March 2020

Dear Professor Kaplan,

Re. "Predicting readmission to intensive care after cardiac surgery; a systematic review."

I attach the above manuscript for consideration of publication in the Journal of Cardiothoracic and Vascular Anaesthesia. Readmission to intensive care after cardiac surgery is an important outcome for both patients and health care organisations. Accurately identifying patients who are at high-risk for readmission to ICU is an important step in trying to avoid this event and improve outcomes associated with it.

Research has already been undertaken to this end, but a systematic review of this topic has not previously been performed. This systematic review summaries risk factors for readmission to intensive care and the impact of readmission on outcomes. It includes all published studies that have performed multivariable analyses to identify risk factors for readmission and focusses on developed clinical prediction models.

We think that the information included in this manuscript will be of significant interest to your readership and is likely to be well cited. We would also hope that this review would provide a sound basis for further research into reducing rates of ICU readmission and improving clinical outcomes.

This manuscript has not been published elsewhere or submitted to any other journal. All authors have approved the manuscript for submission and take responsibility for the data presented to the Journal of Cardiothoracic and Vascular Anaesthesia. This work was supported by British Heart Foundation Grant no: PG/16/80/32411 and there are no other conflicts of interest.

Yours sincerely,

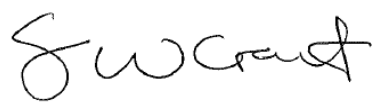

Mr Stuart Grant MBChB (Hons), MRCS, PhD

Academic Clinical Lecturer in Cardiothoracic Surgery

Linda Kimani

Samuel Howitt

Charlene Tennyson

Richard Templeton

Charles McCollum

Stuart Grant 
$4^{\text {th }}$ January 2021

Dear Professor Kaplan,

Re. "Predicting readmission to intensive care after cardiac surgery; a systematic review."

We attach the above revised manuscript for publication in the Journal of Cardiothoracic and Vascular Anaesthesia.

This manuscript has not been published elsewhere or submitted to any other journal. All authors have approved the manuscript for submission to the Journal of Cardiothoracic and Vascular Anaesthesia.

This work was supported by British Heart Foundation Grant no: PG/16/80/32411 and there are no other conflicts of interest.

Yours sincerely,

Linda Kimani

Samuel Howitt

Charlene Tennyson

Richard Templeton

Charles McCollum

Stuart Grant 
Manuscript Number: JCVA-D-20-00378R1

Predicting readmission to intensive care after cardiac surgery: A systematic review

Editor and Reviewer comments:

\section{Section Editors}

Thank you for this submission.

Please revise - respond to the reviewers in a point-by-point fashion.

Please make clear in the title, abstract, and throughout the revised paper that the focus is readmission to intensive care after cardiac surgery within the same hospitalization.

We thank you for this suggestion, the revised manuscript now clarifies throughout that we are referring to readmission within a single hospitalization.

\section{Reviewer 1:}

1. The reviewers have clarified many of my comments and the review is much improved.

We thank the reviewer for this comment.

2. Overall, the results are expected; that older patients, those with renal failure, low EF, DM, etc have a higher risk of re-admission to the CICU.

3. I have two general comments:

The introduction states that the main purpose of the review is to determine predictive variables but in results this is reported last. The intro should be consistent and identify that mortality, length of stay and cause were variables of interest.

We agree that presenting the predictive variables last diminished their importance in the results section. As this is the focus of the review, we have therefore adjusted the results section to present these variables first. Page 2 line 23 now includes mortality, length of stay and readmission causes as variables of interest.

The predictors are the variable most subject to confounding so maybe the main result or focus of the review should be to better characterize causes of readmission and effect on the population?

We agree a review that better characterises the causes for readmission and effect on the population would be useful. However, the primary objective of this review is to identify risk factors associated with readmission to $\mathrm{CICU}$ and models that may be useful when aiming to identify those patients who are at risk of readmission. A better understanding of these risk factors and existing models is vital to future risk prediction work which aims to reduce readmissions to $\mathrm{CICU}$ following cardiac surgery. It is anticipated that this review forms the basis of such future work.

4. While this has not been done before, these results are not a surprise, in fact they are similar to preoperative predictors of morbidity. The question of why looking at re-admission only - why it 
is clinically important should be better addressed.

We thank the reviewer for this suggestion, page 2 line 14 to 16 highlight the key clinical importance of readmissions which include increased mortality in readmitted than nonreadmitted patients, (Rosenberg,2000 and Elliot, 2014) and the unexpected strain on resources (Onwochei,2020). These factors are associated with perioperative morbidity but prevention or planning of readmission may contribute to reduced overall mortality and morbidity following cardiac surgery.

5. Is the abstract in JCVA format?

Yes the abstract is unstructured in line with the JCVA online guide for authors

6. This can be shorted to simply say that "a systematic review of studies identifying risk factors for readmission to $\mathrm{CICU}$ after cardiac surgery has not previously been published".

"In non-cardiac patients, initial admission to intensive care after elective surgery is much less common. Unplanned admission or readmission to general intensive care in this cohort however occurs in $4-14 \%$ of patients. 6 A systematic review of risk factors for unplanned admission or readmission to general intensive care has been performed."

Thank you for this suggestion. We agree that this section was difficult to follow so we have reworked it on Page 2 line 17 to 24.

\section{Reviewer 3:}

Authors addressed Reviewer comments in a comprehensive and thoughtful manner. As a result, the manuscript organization, clarity, and focus has improved. Thank you for this kind comment.

\section{Reviewer 6:}

1. The authors revised the manuscript substantially and extensively, clearing out many of the reviewers' comments. Thank you.

We thank the reviewer for this comment.

2. The fact that so few studies include numbers of enrolled patients is strange and questions the (statistical) validity of these studies.

In the summary of included studies (table 1 ) the patient population column details the numbers of enrolled patients. This is described in all the studies included in this review.

3. When patients are at risk for readmission, as the authors list up the most important risk factors from the literature, it should also be questioned whether these factors were not yet present at the time of discharge of the patients from the ICU. Was there a checklist before discharge of the patients?

The timing of when risk factors were assessed was inconsistent, which was a limitation of this review however Page 7 line 21 in the manuscript clarifies that physiological risk factors were recorded prior to initial discharge for $\mathrm{CICU}$ in 5 studies. We addressed the variable timings of risk factors by grouping the risk factors as preoperative, intraoperative and postoperative. All preand intraoperative risk factors were evidently present prior to initial $\mathrm{CICU}$ discharge. Postoperative predictors, where included, were for the most part also available prior to $\mathrm{CICU}$ discharge. No study described the use of a checklist prior to the discharge of patients from the $\mathrm{CICU}$ at the end of their initial stay. 
4. A better follow up before discharge could have prevented readmission. Therefore, it could be strongly questioned whether prediction of readmission should not be brought back to a correct estimation of discharge-fitness after cardiac surgery. The latter could be integrated in a discharge-score, including screening of the most important organ systems and presence of some limited acute readmission causes (such as late tamponade, progressive heart failure, sepsis/septic or cardiogenic shock, rhythm disturbances necessitating additional therapy. Additional search in the literature on discharge criteria - a correct discharge is always with the aim of preventing readmission - is therefore an important issue in this respect. Please comment.

We agree wholeheartedly that assessment of fitness for discharge is a vital component for preventing potentially avoidable readmissions. One goal of this review is to identify factors which are present at the time of discharge and which are associated with increased risk of readmission. Future work can focus on the development of tools, similar to those you describe, which aim to recognise potentially unsafe discharges before they are made. During this review we identified many studies which define readmission as any readmission occurring at any time during a single hospitalization. This includes 'late readmissions' which occur beyond 72 hours and are less influenced by discharge fitness and more likely to be related to ward level factors. Therefore, as explored in our discussion we believe it is important to separate admissions according to the time at which they occur. Any tool aimed to ensure "discharge-fitness" should probably be based on risk factors known to be associated with earlier readmission.

5. Another point is the fact that in reality an acute readmission should be differentiated from a non-acute readmission. Also, these issues must be commented and checked in the literature for further details.

Thank you for this point. Again, we agree acute readmission should be separated from planned or delayed readmissions. This distinction is not clear in the studies in this review however it has been looked at in non-cardiac surgery patients readmitted to general ICU. We identify this lack of clarity as a weakness in the literature and as an area to be explored in future research. We have now emphasized this point on Page 15 line 4 to 6 .

Renal insufficiency was not defined in terms of the RIFLE criteria (remark 5), which is essential in modern medicine to estimate the degree of failure. Similarly, respiratory complications should be differentiated as not all respiratory failure could result in readmission (remark 5).

We agree that this is a weakness of the studies included in this review. Renal insufficiency was reported in terms of various increases creatinine criteria which may be used to classify the insufficiency by the RIFLE criteria. Unfortunately, the term renal failure also encompassed the requirement for hemofiltration in several studies, therefore we could not group all the definitions by the RIFLE criteria. Similarly, pulmonary dysfunction was variably reported from requirements for intubation/ ventilation to aetiological causes for dysfunction and these groups were not consistently reported independently. We have emphasized the importance of using standardized definitions in future work on this subject. Page 15 line 19-24. 


\section{Predicting readmission to intensive care after cardiac surgery}

\section{within index hospitalization: A systematic review}

Miss. Linda Kimani $M B B S, M R C S^{1}$, Dr. Samuel Howitt $P h D F R C A^{1,2}$, Miss. Charlene Tennyson MBBS, MRCS 3 , Dr. Richard Templeton FRCA, FFICM ${ }^{2}$, Professor. Charles McCollum MD, FRCS ${ }^{1}$ Mr. Stuart W. Grant PhD FRCS(cth) ${ }^{1}$.

1. Division of Cardiovascular Sciences, University of Manchester, ERC, Manchester University Hospital Foundation Trust, Manchester, M23 9LT, UK.

2. Department of Cardiothoracic Anaesthesia and Critical care, Wythenshawe Hospital, Manchester University Hospital Foundation Trust, Manchester, M23 9LT, UK.

3. Department of Cardiothoracic Surgery, Blackpool Victoria Hospital, Whinney Heys Rd, Blackpool, FY3 8NR, UK.

\section{ADDRESS FOR CORRESPONDENCE}

Miss Linda Kimani

Academic Surgery Unit, ERC, Wythenshawe Hospital, Manchester, M23 9LT, UK

Tel: +441612915853 , Fax: +441612915854

Email: linda.kimani@manchester.ac.uk

\section{FUNDING STATEMENT}

This work was supported by the British Heart Foundation grant number PG/16/80/32411.

Declarations of interest: None

ARTICLE TYPE: Regular review 
Predicting readmission to intensive care after cardiac surgery within index hospitalization: A systematic review

\begin{abstract}
Readmission to the cardiac intensive care unit (CICU) after cardiac surgery has significant implications for both patients and healthcare providers. Identifying patients art risk of readmission could potentially improve outcomes. The objective of this systematic review was to identify risk factors and clinical prediction models for readmission within a single hospitalization to intensive care after cardiac surgery. PubMed, MEDLINE and EMBASE databases were searched to identify candidate articles. Only studies that utilised multivariable analyses to identify independent predictors were included.

There were 25 studies and five risk prediction models identified. The overall rate of readmission pooled across the included studies was $4.9 \%$. In all 25 studies, in-hospital mortality and duration of hospital stay were higher in patients who experienced readmission. Recurring predictors for readmission were; preoperative renal failure, age $>70$, diabetes, chronic obstructive pulmonary disease, preoperative left ventricular ejection fraction $<30 \%$, type and urgency of surgery, prolonged cardiopulmonary bypass time, prolonged post-operative ventilation, postoperative anaemia and neurological dysfunction. The majority of readmissions occurred due to respiratory and cardiac complications. Four models were identified for predicting readmission, with one external validation study. As all models developed to date have limitations, further work on larger datasets is required to develop clinically useful models to identify patients at risk of readmission to CICU after cardiac surgery.
\end{abstract}


1

2

3

4

7

8

10

11

12

13

14

15

16

17

18

19

20

21

22

23

24

25

26

27

28

29

30

31

32

33

34

35

36

37

38

39

40

41

42

43

44

45

46

47

48

49

50

51

52

53

54

55

56

57

58

59

60

61

62

63

64 


\title{
Predicting readmission to intensive care after cardiac surgery within
} index hospitalization: A systematic review

\begin{abstract}
Readmission to the cardiac intensive care unit (CICU) after cardiac surgery has significant implications for both patients and healthcare providers. Identifying patients art risk of readmission could potentially improve outcomes. The objective of this systematic review was to identify risk factors and clinical prediction models for readmission within a single hospitalization to intensive care after cardiac surgery. PubMed, MEDLINE and EMBASE databases were searched to identify candidate articles. Only studies that utilised multivariable analyses to identify independent predictors were included.

There were 25 studies and five risk prediction models identified. The overall rate of readmission pooled across the included studies was $4.9 \%$. In all 25 studies, in-hospital mortality and duration of hospital stay were higher in patients who experienced readmission. Recurring predictors for readmission were; preoperative renal failure, age $>70$, diabetes, chronic obstructive pulmonary disease, preoperative left ventricular ejection fraction $<30 \%$, type and urgency of surgery, prolonged cardiopulmonary bypass time, prolonged post-operative ventilation, postoperative anaemia and neurological dysfunction. The majority of readmissions occurred due to respiratory and cardiac complications. Four models were identified for predicting readmission, with one external validation study. As all models developed to date have limitations, further work on larger datasets is required to develop clinically useful models to identify patients at risk of readmission to CICU after cardiac surgery.
\end{abstract}




\section{INTRODUCTION}

Over the past two decades the in-hospital mortality rate after cardiac surgery has declined despite an increase in the risk profile of patients undergoing surgery. ${ }^{1,2}$ This is likely to be due to advances in surgical techniques, perioperative management and postoperative care supported by improved clinical governance processes. Admission to a cardiac intensive care unit $(\mathrm{CICU})$ is routine after cardiac surgery due to the physiological derangement induced by surgery, patient co-morbidities and the relatively high risk of significant early complications.

The majority of patients have a short stay on $\mathrm{CICU}$, they are then transferred to a ward environment before ultimately being discharged home. The decision to deescalate care from $\mathrm{CICU}$ to the ward setting is usually dependent on clinical judgement but can be facilitated by decision support protocols. Following transfer to the ward from $\mathrm{CICU}$ some patients will experience complications that require readmission to $\mathrm{CICU}$ within a single hospitalization. These unplanned readmissions place an unexpected strain on resources, reduce system efficiency and are a significant setback to patients. ${ }^{3-5}$

Readmission to general critical care units following surgery has been the subject of a systematic review.5,6 Although one study included in that review included a subgroup of cardiac surgery patients, ${ }^{7}$ a systematic review of studies identifying risk factors for readmission to $\mathrm{CICU}$ after cardiac surgery has not previously been published. The primary objective of this systematic review was therefore to identify risk factors associated with, or models designed to predict, readmission to $\mathrm{CICU}$ following cardiac surgery. The secondary objectives were to report common causes for readmission, associated mortality and length of stay. 


\section{METHODS}

\section{Search Strategy and Data Sources}

The Cochrane library database of reviews and PubMed health database were searched using the terms, 'readmission', 'cardiac surgery', 'intensive care' for review articles between 1995 and 2019. We then searched MEDLINE and EMBASE using OVID the online library of databases. The search terms 'cardiac surgery', 'readmission' and terms for risk prediction models as recommended by Geersing et. al were used. ${ }^{8}$ The search strategy is detailed in Appendix 1. Titles in English and including readmission to intensive care were identified and selected. The reference lists of the eligible studies were searched to identify additional studies. The abstracts were then reviewed and assessed against the selection criteria.

\section{Selection Criteria}

All studies that reported readmission to intensive care after adult cardiac surgery were assessed for inclusion in the study. The inclusion criteria were: (1) adult patients who underwent cardiac surgery (2) reporting of readmission to CICU after during a single hospitalization as an outcome (3) reporting of multivariable analyses performed to identify risk factors for readmission. The exclusion criteria were: (1) inclusion of medical admissions or other surgical patients in the same cohort as the cardiac surgery patients (2) a lack of identification of factors associated with readmission (3) investigation of readmission to ICU after discharge from hospital (4) exclusion of papers looking at ICU admission following failed fasttrack care in a non ICU setting.

\section{Terms and definitions}

Risk factor- any variable assessed for its influence on readmission to intensive care. The Society of Thoracic Surgeons (STS) database definitions were used by most 
studies to define risk factors. ${ }^{9}$ Where a study applied a separate definition, this was specified. Readmission cause- adverse event that resulted in return to ICU (planned or unplanned) within a single hospitalization. Independent predictor- a variable identified as significantly associated with readmission to ICU on multivariable analysis.

\section{Data extraction and Quality Assessment}

The articles for inclusion were selected by independent reviewers LK, SH and CT. Data were extracted using a framework detailed in appendix 2 . The review was structured according to the Checklist for critical Appraisal and data extraction for systematic Reviews of prediction Modelling Studies (CHARMS) and the Preferred Reporting Items for Systematic reviews and Meta-Analyses(PRISMA) guidance. ${ }^{10,11}$ The following elements of each study were reviewed and reported; aim, outcome definition, follow-up, loss to follow-up, data collection (consecutive, prospective), prospective calculation of study size, inclusion criteria, control group and statistical analyses. The level of bias was reported using the QUIPS(Quality in Prognostic Studies) tool for risk factor analysis studies whereas for studies that included a risk prediction model, the PROBAST (Prediction model Risk Of Bias ASsessment Tool) was used. ${ }^{12,13}$

Patient-level readmission data from each study were summarized to provide the total readmission rate across all studies. The causes for readmission were grouped into organ-specific classes; respiratory, cardiac, renal, gastrointestinal, neurological, sepsis and return to theatre. "Return to theatre" was used as an umbrella term to categorise all causes for readmission that required further surgical intervention such as bleeding, cardiac tamponade or sternal re-suturing. The raw data on causes for 
readmission were extracted from each study. Mortality and length of stay data were presented as median and interquartile ranges.

\section{Model analysis}

Where a clinical prediction model was identified, the CHARMS checklist was used to extract data from the manuscript. ${ }^{10}$ Data on independent predictors including method of selection, events per variable (EPV) ratio, development and validation population, methods, statistical performance, model evaluation and model delivery methods (clinical risk scores/ risk indexes) were extracted. The adherence of the model publication to TRIPOD guidelines was also assessed. ${ }^{14}$ Statistical performance related to discrimination was assessed using area under the receiver operating characteristic curve (AUC) with an AUC value of $>0.7$ defined as acceptable. Measures of calibration extracted included the Hosmer-Lemenshow (HL) test result, ${ }^{15}$ calibration plot performance and $\mathrm{R}^{2}$ score. ${ }^{16,17}$

\section{RESULTS}

\section{Selected Studies}

There were no existing Cochrane, Centre for Reviews or PubMed Health registered reviews summarising risk factors or prediction models for readmission to intensive care after cardiac surgery. The process detailing the selection of studies is outlined in Figure 1.

\section{Study quality and population characteristics}

Twenty-five studies met the inclusion criteria. Details regarding these studies and the population characteristics are summarized in Table 1 and Table 2. Most studies were performed in academic institutions (86\%). The studies identified were carried out in Europe (48\%), North America (28\%) and Asia (24\%). All studies included were 
observational. The majority (86\%) were cohort studies with the rest performed using case-control methodology. Of the included studies, $83 \%$ were performed retrospectively. Data were collected consecutively in 13 studies with this information not provided in the other 12 studies. The majority (60\%) of studies recruited patients who were operated on within the most recent decade (2010-2020) with the rest performed prior to 2010. The handling of missing data was only reported in five studies. The study size varied from 80 to 10,992 . Sample size calculation was included in one study.$^{18}$ All studies described preoperative patient demographics. The overall risk of bias was low in 21 (72\%) of the included studies.

\section{Outcome definitions}

All readmissions during a single hospitalization were considered irrespective of timing. No study defined a time period in which readmission to the CICU needed to occur in order to be classified as "Readmission to CICU". The period spent on the ward was reported in 6/25 studies and one study grouped readmission time by period from discharge. ${ }^{18-24}$ Given that the same patient can potentially be readmitted to ICU on more than one occasion, eight studies also reported the number of unique patients who experienced readmission.

\section{Readmission rates and causes}

The readmission rate pooled across all studies was $4.9 \%$. Two studies compared readmission rates between specific procedure groups; Boeken et al reported readmission rates of $4.0 \%$ following off-pump coronary artery bypass (OPCAB) compared to $4.80 \%$ following minimally invasive procedures and Hui et al reported a a readmission rate of $18.4 \%$ following LVAD insertion. ${ }^{18,25}$ In contrast, for the three studies that only studied readmission after CABG procedures the rate of readmission 
ranged from $3.6 \%$ to $6.6 \%$. The remaining studies assessed readmission following mixed adult cardiac surgery.

Causes for readmission were reported in 16 studies and grouped into organ-specific classes; respiratory, cardiac, renal, gastrointestinal, neurological, sepsis and return to theatre. Table 1 shows the most frequent cause documented in each study and Figure 2 details the overall frequency of causes across all studies. Respiratory complications were the most frequent cause of readmission $(n=11)$. The proportion of readmissions for which respiratory complications were responsible ranged from $18.0 \%$ to $53.3 \%$. The proportion of readmissions that were due to cardiac complications ranged from $22.9 \%$ to $35.6 \%$ in the 6 studies that reported this information. Similarly, return to theatre was associated with $6.4 \%$ to $15.9 \%$ of readmissions. Across the studies the propotions of readmissions due to other casues were; neurological $2.2 \%$ to $15.2 \%$, renal $2.4 \%$ to $23.0 \%$, gastrointestinal $2.4 \%-7.9 \%$ and sepsis $1.4 \%$ to $15.6 \%$. One study assessed differences in mortality rates based on reason for readmission and demonstrated that patients readmitted due to renal complications had a higher mortality $(46 \%)$ than patients readmitted with cardiovascular (31\%) or respiratory complications $(22 \%) .{ }^{26}$

\section{Risk factors and predictors of readmission}

All studies investigated pre and post-operative risk factors associated with readmission. Intra-operative risk factors were investigated in 24 studies. The identified risk factors for readmission are detailed in Figure 3. Physiological variables recorded prior to initial $\mathrm{CICU}$ discharge were included in five studies; these variables were measured at a single time-point in four studies and one study included continuous variables with temporal trends. ${ }^{21,27-30}$ Nurse staffing levels, time of discharge from ICU and bed availability were each investigated in two separate 
studies and were not found to be significant predictors for readmission. ${ }^{31,32}$

Preoperative variables found to be associated with readmission in four or more studies were (in order of frequency); preoperative renal failure, chronic obstructive pulmonary disease, age $>70$, New York Heart Association classification (NYHA) >III, ejection fraction $<40 \%$ and procedure urgency. Postoperative respiratory complications including prolonged mechanical ventilation and pneumonia prior to initial discharge from ICU were the most frequent postoperative variables identified as a risk factor in six studies. In the 11 studies that reported the median initial length of ICU stay, readmitted patients has initially stayed in ICU for 2 to 9 days and nonreadmitted patients for 1 to 4 days and prolonged initial ICU stay was a predictor of readmission.

\section{Models to predict readmission to ICU after cardiac surgery}

Five risk prediction models developed to predict readmission to ICU were identified. The models are described in detail using the CHARMS criteria in Table 2 and summarized below.

\section{BAT model ${ }^{31}$}

The BAT (Bounce back After Transfer) model was developed to predict unplanned cardiac surgery readmissions. The BAT score includes the following variables; female, NHYA III/V, urgent or emergent operative status and postoperative renal failure during index $\mathrm{CICU}$ admission, allowing it to be calculated at the end of the CICU stay. It was developed using data from 421 adult cardiac surgery patients who underwent coronary artery bypass grafting or aortic valve replacement in the USA. The rate of unplanned readmission following discharge from CICU to the ward was $6.6 \%$. The model showed good discrimination (AUC 0.81), and had an R2 of 0.86 in the development population. The model has not been externally validated to date. 


\section{APPROACH model ${ }^{28,29}$}

The APPROACH (Alberta Provincial Project for Outcomes Assessment in Coronary Heart Disease) model, was developed from data for all adult patients undergoing cardiac surgery in a single province in Canada between 2004 and 2012. The risk score is designed to be calculated at the time of initial discharge from $\mathrm{CICU}$ and includes postoperative events (deep sternal wound infection, gastrointestinal bleed, cardiac arrest, pneumonia, pleural effusion, neurological complications and leg graft harvest site infection) alongside measured variables (ejection fraction $<20 \%, 20-34 \%$, age $>90,80-89,70-79$, chronic lung disease, single valve/non-CABG surgery, multiple valve surgery). There were 10,799 patients included in the dataset used for development and validation of the model. The readmission rate in the study population was $4.4 \%$. Following internal validation using bootstrapping, the model showed good discrimination ( $A \cup C=0.80$ ) and adequate calibration according to the $\mathrm{H}-\mathrm{L}$ test. The model was validated externally in a cohort of 805 patients with a readmission rate of $4.6 \%{ }^{29}$ The APPROACH model demonstrated good discrimination $(A \cup C=0.75$ ) but poor calibration according to the $\mathrm{H}-\mathrm{L}$ test.

\section{Refined APPROACH model ${ }^{29}$}

The APPROACH model was refitted by verma et al to include the following additional variables; re-intubation, tracheostomy, oxygen at discharge, inotropes at discharge, heart rate and systolic blood pressure. The refitted model including all the additional variables resulted in a slight improvement in discrimination (AUC 0.77) compared to the development set. The addition of systolic blood pressure at the time of discharge resulted in the largest improvement in discrimination $(A \cup C=0.78)$ and adequate calibration according to the $\mathrm{H}-\mathrm{L}$ test. The refined model has not been externally validated. 


\section{Thomson model $2018{ }^{30}$}

The study comprised of 4,869 patients, who had undergone cardiac surgery procedures at a single centre in the United Kingdom. The final score included the following risk factors; operative urgency, diabetes, chronic kidney disease stage 3-5, hypertension, logistic EuroSCORE,the Intensive Care National Audit and Research Centre(ICNARC) score, preoperative neurological disease, aortic valve surgery and postoperative anaemia. The risk of readmission can be calculated at any point during the CICU stay. The readmission rate was 3.2\%. The authors reported that bootstrapped model was well calibrated with good discrimination but details on statistical performance were not provided. This model has not been externally validated to date.

\section{Li model 201933}

This model was developed to predict the risk of CICU readmission after valve surgery in China. The derived risk score includes age $>65$, chronic lung disease, previous cardiac surgery, LVEF $<50 \%, \mathrm{LVEF}<40 \%$, NHYA III/IV, multiple valve repair/replacement, cardiopulmonary bypass time $>180$ minutes, cardiac arrest, ARDS, pneumonia, deep sternal wound infection and postoperative renal failure. All variables are collected during the index admission to $\mathrm{CICU}$ allowing the score to be calculated prior to ward transfer. The model was developed and internally validated in 1216 patients. The rate of readmission was higher than in other studies at $13.4 \%$. The model demonstrated good discrimination $(A \cup C=0.88)$ in the same institution in a cohort of patients observed at a different time $(n=382)$ and was adequately calibrated according to the $\mathrm{H}-\mathrm{L}$ test. This model has not been externally validated to date. 


\section{Mortality and length of stay following readmission}

The mortality rate for patients who experienced readmission was reported in all studies. Patients who were readmitted to $\mathrm{CICU}$ had a higher in-hospital mortality rate (median 15.4\%, IQR 12.10-19.30), than those who were not (median 1.4\%, IQR 0.33.1). A single study reported 1-year mortality which was also higher in the readmitted group (21.0\% vs $4.2 \%) .{ }^{28}$ In-hospital length of stay was reported in 11 studies and was longer in the readmitted group for all studies. The median time between initial discharge from ICU and readmission was reported in 6/25 studies and ranged from 3-7 days. In the one study that reported readmissions grouped by time, the majority were readmitted within the first 24 hours of discharge from $\mathrm{CICU}(47.2 \%) .{ }^{19}$ The duration of the second ICU stay following readmission after standard care was reported in five studies and ranged from 6 to 13 days.

\section{DISCUSSION}

Approximately $5 \%$ of patients in the studies identified in this review experienced readmission to $\mathrm{CICU}$. The most common causes of readmission were respiratory or cardiac complications. Readmission to CICU was consistently associated with prolonged in-hospital length of stay and an increased risk of in-hospital mortality. This review has identified the important risk factors related to CICU readmission and five models designed to predict readmission. Of the five models identified, only one has been externally validated.

Readmission to CICU was uniformly defined as a second admission to $\mathrm{CICU}$ during a single hospitalization in all studies. However, the timing of readmission relative to the initial discharge from $\mathrm{CICU}$ was only reported in six studies. The benchmark of unplanned readmission to $\mathrm{CICU}$ within 48 hours of discharge which is used as a marker of quality of care, could therefore not be evaluated in this review. ${ }^{4}$ The timing 
of readmission and variation in risk factors associated with readmission at different times relative to initial $\mathrm{CICU}$ discharge has been evaluated by a number of authors. Brown et.al suggested two full calendar days is the optimal time interval for attributing readmission to ICU rather than ward related factors. ${ }^{34}$ Later readmission (>72hours after ICU discharge) has been suggested to be more closely related to patient factors such as baseline comorbidities and ward care. ${ }^{35}$ Although there was a lack of distinction in timing of readmission, independent risk factors were common across studies. Of the pre-operative risk factors, renal failure was the most common risk factor with other common risk factors including age $>65$, hypertension, raised body mass index $>27$, aortic valve surgery. However, overall, post-operative factors tended to demonstrate more significant influence on the risk of readmission to ICU. The largest study included found that postoperative events contributed to the majority of the readmission risk in comparison to intraoperative and preoperative factors. ${ }^{28}$ Postoperative renal failure (defined variably as use of renal replacement therapy or raised serum creatinine concentration) was included as a risk factor in four of the models included in this review.

Post-operative physiological data were included in two models. The model by Thompson et al, includes the ICNARC postoperative physiology score. ${ }^{30}$ Postoperative physiological variables have also been shown to be useful for predicting other complications after cardiac surgery. ${ }^{36}$ Xue et. al demonstrated that inclusion of temporal trends in post-operative physiological measurements improved model performance compatred with models solely based on snapshots of physiological values. $^{27}$

Although not included in the identified models, the effect of the duration of the initial $\mathrm{CICU}$ admission on the risk of subsequent readmission has also been investigated. 
Some studies suggested that 'premature' discharges were associated with increased risk of adverse outcomes. ${ }^{6,34}$ However in a study of on-pump CABG patients, those who were discharged on post-operative day zero or day one did not have an increased risk of adverse outcomes or mortality at 30-days compared to those discharged on post-operative day two. ${ }^{32}$ In this review we identified three studies that demonstrated prolonged initial CICU stay was an independent risk factor for readmission to $\mathrm{CICU}{ }^{24,37,38}$

Risk factors for readmission are related to but different from causes for readmission and we have assessed both in this review. The most common causes for readmission were respiratory or cardiac complications. Readmission to $\mathrm{CICU}$ is normally deployed in patients who experience severe complications to facilitate more intensive monitoring and treatments. As such, failure to rescue (FTR) which is defined as the inability to prevent death after the development of a complication is intimately related to readmission to $\mathrm{CICU}{ }^{39}$

Patients who deteriorate on the ward can either be readmitted to $\mathrm{CICU}$ in an attempt to avoid FTR or may experience FTR without readmission to $\mathrm{CICU}$. Accurate models designed to be applied prior to a patient's discharge from CICU could potentially reduce the incidence of FTR as patients who experience complications in a CICU environment are more likely to be rescued than those who deteriorate in a ward environment. ${ }^{40}$ Models based on data collected after discharge from $\mathrm{CICU}$, such as early warning scores are likely to be better suited to identifying patients at risk of FTR late after $\mathrm{CICU}$ discharge. However, all models identified in this review were based on data up to the point of discharge from $\mathrm{CICU}$ with none including ward level factors. 
Of the five models identified, only a single model has been externally validated to date and no examples of model application in a clinical trial or impact study were identified. The lack of clinical translation may be related to statistical challenges. Firstly, readmission to $\mathrm{CICU}$ after cardiac surgery is a rare event. To maximize the chance that any model to predict readmission will transfer well to other institutions, the model design cohort should have an appropriate sample size and ratio of events per variable (EPV) value of 10 or greater. ${ }^{41}$ Only two of the five studies included a sample size calculation and three of the included models had an EPV of less than five. ${ }^{42}$

Most models identified were internally validated using a random split approach in the same population, which rarely achieved the suggested number of events $(>100$ outcomes) and limited the analysis of variable shrinkage in the development datasets. ${ }^{30,31,33}$ Another consideration given the low incidence of the outcome is that the datasets used for model development and validation are inherently unbalanced. As a result discrimination may potentially appear excellent solely due to a model correctly identifying a high number of patients as being at low-risk of readmission. ${ }^{43}$ Going forward, precision recall curve analysis is likely to be a more appropriate tool to assess model performance in this setting .

\section{Limitations of this review}

There are a number of methodological limitations that have prevented a metaanalysis of the studies included in this review. All the included studies were of an observational design, the majority were retrospective with variable outcome reporting which distorted the baseline risks to readmission and increased the chances of missing data. Secondly, a number of the included studies did not report how missing 
data was handled. This limited the statistical conclusions and prevented pooling of the outcomes across studies.

The definition of "readmission to CICU" encompasses a relatively heterogenous groups of patients. As mentioned previously, those admitted within 48 hours of discharge are likely to have different reasons for readmission and different outcomes to those readmitted after a longer period on the ward. Further in-depth analysis of risk factors in patients re-admitted at different time points after initial discharge to the wards was not possible in this review. However, although re-admission to CICU is a relatively heterogenous outcome influenced by patient and institution level factors, it is clearly an important outcome associated with both morbidity and mortality.

Evidence gaps and key questions for future clinical trials

The definition of readmission used in this study ensured inclusion of patients who experienced this complication at any time but also resulted in the aggregation of a number of potentially diverse groups. A time-specific definition of readmission will improve research into prediction of readmission to CICU. Future studies that explore risk factors related specifically to 'early readmissions', 'late readmissions' or 'recurrent readmissions' may also highlight key differences in these groups. For example models to prevent "unsafe" discharges from CICU may perform better if designed to focus on risk factors associated with early readmission. Risk factor analysis would also be improved by the use of standardized definitions for independent variables and clear time-points for recording them. This may be particularly important when evaluating the importance of renal and respiratory dysfuction which were defined inconsistently throughout the studies identified in this review. 
FTR rates in postoperative patients have been shown to be influenced by institutional level factors such as hospital teaching status, hospital technology level, nurse-patient ratios and ICU bed capacity rates. ${ }^{44}$ These hospital-level variables are challenging to measure and an unobserved source of confounding around the act of readmitting a patient to $\mathrm{CICU}$. Although not explored in the studies in this review, research into FTR rates and CICU readmission may offer insights into differences between rates and outcomes of readmission to $\mathrm{CICU}$ after cardiac surgery that are related to institutional level differences. ${ }^{39,45-47}$

Most studies identified in this review excluded those who died during the index ICU admission or on the ward without being readmitted to $\mathrm{CICU}$, without adjustment for the competing risk to mortality. This means that a patient who died on a ward without readmission to $\mathrm{CICU}$ in one institution (as so was excluded from a study) might have been readmitted to $\mathrm{CICU}$ and included in a similar study in a different institution. Investigating this concept in future studies would improve the understanding of mortality associated with readmission to ICU 48

\section{CONCLUSIONS}

Approximately 1 in 20 cardiac surgery patients will experience readmission to $\mathrm{CICU}$. Readmission to $\mathrm{CICU}$ is associated with an increased risk of mortality, prolonged length of stay and poorer outcomes in these patients. Respiratory deterioration was the most frequent cause for readmission in the studies included. Renal dysfunction (both pre-operative and post-operative) was the most consistent predictor of readmission. The models identified in this review may be useful in benchmarking institutions, however further research is required on external validation and to establish their utility in clinical practice. 


\section{Figure Legends}

Figure 1: Study selection flow diagram

Figure 2: Median percentage of readmissions due to specific causes (when specified) across included studies.

Figure 3: Number of studies identifying specific risk factors readmission to CICU on multivariable analysis.

\section{Supplementary material}

Appendix 1: Readmission to ICU after cardiac surgery- Online databases search terms

Appendix 2: Data Extraction form

Appendix 3: PRISMA checklist 


\section{References:}

1. National Cardiac Audit Programme(NCAP) National institute for cardiovascular outcomes(NICOR).Retrieved from: https://www.nicor.org.uk/national-cardiac-audit-programme/(accessed 13/08/2019)

2. Richens D Cardiothoracic Surgery GRIFT Programme National Speciality Report 2018.Retrieved from: https://gettingitrightfirsttime.co.uk/surgicalspecialty/cardiothoracic-surgery/(accessed 01/01/19)

3. The Intensive Care National Audit and Research Centre.ICNARC-Annual quality report 2017/2018 for adult cardiothoracic critical care.Retrieved from: https://onlinereports.icnarc.org/Reports/2018/12/annual-qualityreport-201718-for-adult-cardiothoracic-critical-care(accessed 01/01/2019)

4. Elliott M, Worrall-Carter L, Page K: Intensive care readmission: a contemporary review of the literature. Intensive Crit. Care Nurs. Elsevier, 30:121-37, 2014

5. Onwochei DN, Fabes J, Walker D, et al: Critical care after major surgery: a systematic review of risk factors for unplanned admission. Anaesthesia 75:62-74, 2020

6. Rosenberg AL, Watts C: Patients readmitted to ICUs: a systematic review of risk factors and outcomes. Chest 118:492-502, 2000

7. Hosein FS, Roberts DJ, Turin TC, et al: A meta-analysis to derive literature-based benchmarks for readmission and hospital mortality after patient discharge from intensive care. Crit. Care BioMed Central, 18:715, 2014

8. Geersing G.J, Bouwmeester W, Zuithoff $P$, et al: Search filters for finding prognostic and diagnostic prediction studies in Medline to enhance systematic reviews. PLoS One Public Library of Science, 7:32-84, 2012

9. Shahian DM, Jacobs JP, Edwards FH, et al: The society of thoracic surgeons national database. Heart 99(20):1494-1501,2013

10. Moons KGM, de Groot JAH, Bouwmeester W, et al: Critical appraisal and 
data extraction for systematic reviews of prediction modelling studies: the

11. Moher D, Liberati A, Tetzlaff $\mathrm{J}$, et al: Preferred reporting items for systematic reviews and meta-analyses: the PRISMA statement. J. Clin. Epidemiol.2009

12. Hayden JA, van der Windt DA, Cartwright JL, et al Ann. Intern. Med.158(4):280-284,2013

13. Wolff RF, Moons KGM, Riley RD, et al: PROBAST: A tool to assess the risk of bias and applicability of prediction model studies. Ann. Intern. Med.2019

14. Collins GS, Reitsma JB, Altman DG, et al: Transparent reporting of a multivariable prediction model for individual prognosis or diagnosis (TRIPOD): the TRIPOD statement. BMC Med. BioMed Central, 13:1, 2015

15. Scott AJ, Hosmer DW, Lemeshow S: Applied Logistic Regression. Biometrics 1991

16. Murphy AH: A new vector partition of the probability score. J. Appl. Meteorol. 12:595-600, 1973

17. Menard S: Applied logistic regression analysis. Sage, 2002,

18. Hui J, Mauermann WJ, Stulak JM, et al: Intensive Care Unit Readmission After Left Ventricular Assist Device Implantation: Causes, Associated Factors, and Association With Patient Mortality. Anesth. Analg. LWW, 128:1168-74, 2019

19. Kogan A, Cohen J, Raanani E, et al: Readmission to the intensive care unit after "fast-track" cardiac surgery: risk factors and outcomes. Ann. Thorac. Surg. Elsevier, 76:503-7, 2003

20. Cohn WE, Sellke FW, Sirois C, et al: Surgical ICU recidivism after cardiac operations. Chest Elsevier, 116:688-92, 1999

21. Chung DA, Sharples LD, Nashef SAM: A case-control analysis of readmissions to the cardiac surgical intensive care unit. Eur. J. CardioThoracic Surg. Elsevier Science BV, 22:282-6, 2002

22. Litmathe J, Kurt M, Feindt P, et al: Predictors and outcome of ICU readmission after cardiac surgery. Thorac. Cardiovasc. Surg. (C) Georg Thieme Verlag KG Stuttgart· New York, 57:391-4, 2009 
23. Benetis R, Sirvinskas E, Kumpaitiene B, et al: A case-control study of readmission to the intensive care unit after cardiac surgery. Med. Sci. Monit. Int. Med. J. Exp. Clin. Res. International Scientific Information, Inc., 19:148, 2013

24. Jarzabek R, Bugajski P, Greberski K, et al: Readmission to an intensive care unit after cardiac surgery: reasons and outcomes. Kardiol. Pol. (Polish Hear. Journal) 72:740-7, 2014

25. Boeken U, Minol JP, Assmann A, et al: Readmission to the intensive care unit in times of minimally invasive cardiac surgery: does size matter? . Heart Surg. Forum . 17:296-301,2014

26. Litwinowicz R, Bartus $\mathrm{K}$, Drwila $\mathrm{R}$, et al: In-hospital mortality in cardiac surgery patients after readmission to the intensive care unit: a singlecenter experience with 10,992 patients. J. Cardiothorac. Vasc. Anesth. Elsevier, 29:570-5, 2015

27. van Diepen S, Graham MM, Nagendran J, et al: Predicting cardiovascular intensive care unit readmission after cardiac surgery: derivation and validation of the Alberta Provincial Project for Outcomes Assessment in Coronary Heart Disease (APPROACH) cardiovascular intensive care unit clinical prediction. Crit. Care 18:651, 2014

28. Xue Y, Klabjan D, Luo Y: Predicting ICU readmission using grouped physiological and medication trends. Artif. Intell. Med. Elsevier, 95:27-37, 2019

29. Verma S, Southern DA, Raslan IR, et al: Prospective validation and refinement of the APPROACH cardiovascular surgical intensive care unit readmission score. J. Crit. Care.Elsevier, 54:117-21, 2019

30. Thomson R, Fletcher N, Valencia O, et al: Readmission to the Intensive Care Unit Following Cardiac Surgery: A Derived and Validated Risk Prediction Model in 4,869 Patients. J. Cardiothorac. Vasc. Anesth. Elsevier,32(6):2685-2691,2018

31. Magruder JT, Kashiouris M, Grimm JC, et al: A predictive model and risk score for unplanned cardiac surgery intensive care unit readmissions. J. Card. Surg. Wiley Online Library, 30:685-90, 2015

32. Calafiore AM, Scipioni G, Teodori G, et al: Day 0 intensive care unit discharge-risk or benefit for the patient who undergoes myocardial 
revascularization? Eur. J. Cardio-Thoracic Surg. Elsevier Science BV, 21:377-84, 2002

33. Li S, Tang B, Zhang B, et al: Analysis of risk factors and establishment of a risk prediction model for cardiothoracic surgical intensive care unit readmission after heart valve surgery in China: A single-center study. Hear. Lung Elsevier, 48:61-8, 2019

34. Brown SES, Ratcliffe SJ, Halpern SD: An empirical derivation of the optimal time interval for defining ICU readmissions. Med. Care NIH Public Access, 51:706, 2013

35. Ho KM, Dobb GJ, Lee KY, et al: The effect of comorbidities on risk of intensive care readmission during the same hospitalization: A linked data cohort study.J. Crit. Care.Elsevier B.V. 24:101-7,2009

36. Howitt SH, Grant SW, Riding DM, et al: Risk models that utilise postoperative patient monitoring data to predict outcomes in adult cardiac surgery; a systematic review. J. Cardiothorac. Vasc. Anesth. Elsevier, 31(5):1865-1877,2017

37. Gumus F, Polat A, Yektas A, et al: Readmission To Intensive Care Unit After Coronary Bypass Operations in the Short Term. Turkish J. Anaesthesiol. Reanim. Turkish Society of Anaesthesiology and Reanimation, 42:162, 2014

38. Joskowiak D, Wilbring M, Szlapka M, et al: Readmission to the intensive care unit after cardiac surgery: a single-center experience with 7105 patients. J. Cardiovasc. Surg. (Torino). 53:671-6, 2012

39. Ahmed EO, Butler R, Novick RJ: Failure to rescue rate as a measure of quality of care in a cardiac surgery recovery unit: A five-year study. Ann. Thorac. Surg,97(1):147-152, 2014

40. Sharoky CE, Martin ND, Smith BP, et al: The Location and Timing of Failure to Rescue Events Across a Statewide Trauma System. J. Surg. Res, 235:529-535, 2019

41. Collins GS, Ma J, Gerry S, et al: Risk prediction models in perioperative medicine: methodological considerations. Curr. Anesthesiol. Rep. Springer, 6:267-75, 2016

42. Bujang MA, Sa'At N, Tg Abu Bakar Sidik TMl, et al: Sample size 
guidelines for logistic regression from observational studies with large population: Emphasis on the accuracy between statistics and parameters based on real life clinical data. Malaysian J. Med. Sci.2018

43. Roumani YF, Roumani Y, Nwankpa JK, et al: Classifying readmissions to a cardiac intensive care unit. Ann. Oper. Res. Springer, 263:429-51, 2018

44. Sheetz KH, Dimick JB, Ghaferi AA: Impact of hospital characteristics on failure to rescue following major surgery. Ann. Surg, 263(4):692, 2016

45. Edwards FH, Ferraris VA, Kurlansky PA, et al: Failure to rescue rates after coronary artery bypass grafting: an analysis from the Society of Thoracic Surgeons adult cardiac surgery database. Ann. Thorac. Surg.102(2):458464,2016

46. Nayak JG, Holt SK, Wright JL, et al: The impact of readmission hospital on failure to rescue rates following major urologic cancer surgery. Urol. Oncol. Semin. Orig. Investig.36(4):156,2018

47. Reddy HG, Shih T, Englesbe MJ, et al: Analyzing "failure to rescue": is this an opportunity for outcome improvement in cardiac surgery? Ann. Thorac. Surg. Elsevier, 95:1976-81, 2013

48. Maharaj R, Terblanche M, Vlachos S: The utility of ICU readmission as a quality indicator and the effect of selection. Crit. Care Med. 46:749-56, 2018 
Appendix 1

\section{ICU READMISSION- Online databases search terms}

Cochrane search- no results

1. MeSH descriptor: [Coronary Artery Bypass] explode all trees or MeSH descriptor: [Heart Valve Prosthesis] explode all trees or MeSH descriptor: [Cardiac Surgical Procedures] explode all trees

2. MeSH descriptor: [Readmission] explode all trees or MeSH descriptor: [Recidivism] explode all trees.

3. MeSH descriptor: [Decision Making] explode all trees or MeSH descriptor: [Decision Support Techniques] explode all trees or MeSH descriptor: [Bayes Theorem] explode all trees

Medline and EMBASE Search: 810

1. (Heart surg* or Cardi* surg or Coronary artery bypass or Coronary bypass or CABG or Coronary Graft or coronary or OPCAB).

2. (Valve or Tricuspid or Mitral or Aortic or or valve prosth*)

3. aorta, thoracic/ or "sinus of valsalva"/ or aortic aneurysm, thoracic/ or aortic rupture/ or aortic arch syndromes/

4. Cardiac surgery.mp. or Thoracic Surgery/( Limit to human and adult)

5. (Readmission* or Recidivism*).af.

6. (Intensive care or HDU or ICU or CVICU or CICU).af.

7. "analytical, diagnostic and therapeutic techniques and equipment (non mesh)"/ or treatment outcome/ or patient care/ or therapy, computer-assisted/ or anesthesia/ or cardiovascular surgical procedures/ or monitoring, intraoperative/ or perioperative care/ or decision support techniques/ or models, theoretical/ or "health care (non mesh)"/ or outcome reporting.mp. or database.mp. or prognostication.mp. or algorithm.mp. or prediction model.mp. or risk stratification.mp. [mp=title, abstract, original title, name of substance word, subject heading word, floating sub-heading word, keyword heading word, organism supplementary concept word, protocol supplementary concept word, rare disease supplementary concept word, unique identifier, synonyms]

8. 1 or 2 or 3 and 4 and 5 and 6 and $7=4210$

9. Reviews $=810$

10. After title review $=59$ 


\begin{tabular}{|c|c|c|}
\hline Domain & Contents & Descriptor examples \\
\hline Authors & $\begin{array}{l}\text { First Author Surname, Year of } \\
\text { publication, Country of study }\end{array}$ & \\
\hline $\begin{array}{r}\text { Source of } \\
\text { data }\end{array}$ & $\begin{array}{l}\text { Study design } \\
\text { Number of Centers }\end{array}$ & $\begin{array}{l}\text { Cohort, case-control, RCT, Registry data } \\
\text { Single/ Multi-center. University or tertiary } \\
\text { hospital }\end{array}$ \\
\hline Participants & $\begin{array}{l}\text { Recruitment (Period and sequence) } \\
\text { Inclusion and exclusion criteria }\end{array}$ & No. of years, consecutive. \\
\hline $\begin{array}{l}\text { Outcome } \\
\text { predicted }\end{array}$ & $\begin{array}{l}\text { Definition, frequency, blinding of } \\
\text { outcome assessment, timing of outcome }\end{array}$ & $\begin{array}{l}\text { Readmission rate within 48hours of ICU, } \\
\text { blinded researcher }\end{array}$ \\
\hline Predictors & $\begin{array}{l}\text { Type. Univariate selection and retention } \\
\text { in model }\end{array}$ & $\begin{array}{l}\mathrm{P} \text { value }<0.05, \text { forward/Backward } \\
\text { stepwise analysis }\end{array}$ \\
\hline Sample size & $\begin{array}{l}\text { Calculation } \\
\text { Events per variable }\end{array}$ & $\begin{array}{l}\text { Number of outcomes/events in relation } \\
\text { to the number of candidate predictors }\end{array}$ \\
\hline Missing data & $\begin{array}{l}\text { Number of participants with missing } \\
\text { data/ overall percentage of missing data. } \\
\text { Handling of missing data }\end{array}$ & $\begin{array}{l}\text { Complete case analysis (Exclusion of all } \\
\text { records with missing values) } \\
\text { Imputation/Other methods. }\end{array}$ \\
\hline $\begin{array}{r}\text { Model } \\
\text { development }\end{array}$ & Modelling technique & $\begin{array}{l}\text { Logistic regression, Bayes, Machine } \\
\text { learning }\end{array}$ \\
\hline $\begin{array}{r}\text { Model } \\
\text { performance }\end{array}$ & $\begin{array}{l}\text { Calibration } \\
\text { Discrimination } \\
\text { Classification } \\
\text { Priori cut points }\end{array}$ & $\begin{array}{l}\text {-Calibration plot, Calibration slope, } \\
\text { Hosmer-Lemeshow test. } \\
\text { - AUC(C-statistic/index), D-statistic, log- } \\
\text { rank } \\
\text { - Sensitivity, specificity, predictive } \\
\text { values, net reclassification improvement. }\end{array}$ \\
\hline $\begin{array}{r}\text { Model } \\
\text { Evaluation }\end{array}$ & $\begin{array}{l}\text { Validation techniques } \\
\text { Adjustments for poor validation }\end{array}$ & $\begin{array}{l}\text { Internal: random split of data, resampling } \\
\text { methods, e.g., bootstrap or cross- } \\
\text { validation, none } \\
\text { External: temporal, geographical, } \\
\text { different setting, different investigators) } \\
\text { Adjustments: intercept recalibrated, } \\
\text { predictor effects adjusted, or new } \\
\text { predictors added }\end{array}$ \\
\hline Results & $\begin{array}{l}\text { Alternative model presentations and how } \\
\text { they were derived }\end{array}$ & $\begin{array}{l}\text { Equation, including predictor weights or } \\
\text { regression coefficients, intercept, } \\
\text { baseline survival, model performance } \\
\text { measures (with standard errors or } \\
\text { confidence intervals } \\
\text { Sum score, nomogram, score chart, } \\
\text { predictions for specific risk subgroups } \\
\text { with performance }\end{array}$ \\
\hline
\end{tabular}




\section{5 \\ 16 \\ 1PRISMA Checklist}

19

2section/topic

\# Checklist item

Reported on page \#

21

2UTLE

23 title

Checklist item

\section{ABSTRACT}

26 2̧tructured summary

28

29

\section{1 तिTRODUCTION}

32ationale

33

3abjectives

35

36 ETHODS

\section{3rotocol and} 3 ggistration

A1 9 igibility criteria

42

43 fiformation sources

44

45

4 search

47

48

4 f̧udy selection

50

51 ata collection 5 process

54 tata items

55

56

5 Hisk of bias in

$58 d i v i d u a l$ studies

59

6fummary measures

61 synthesis of results

63

64
1 Identify the report as a systematic review, meta-analysis, or both.

2 Provide a structured summary including, as applicable: background; objectives; data sources; study eligibility criteria, participants, and interventions; study appraisal and synthesis methods; results; limitations; conclusions and implications of key findings; systematic review registration number.

3 Describe the rationale for the review in the context of what is already known.

4 Provide an explicit statement of questions being addressed with reference to participants, interventions, comparisons, outcomes, and study design (PICOS).

5 Indicate if a review protocol exists, if and where it can be accessed (e.g., Web address), and, if available, provide registration information including registration number.

6 Specify study characteristics (e.g., PICOS, length of follow-up) and report characteristics (e.g., years considered, 3 language, publication status) used as criteria for eligibility, giving rationale.

7 Describe all information sources (e.g., databases with dates of coverage, contact with study authors to identify additional studies) in the search and date last searched.

8 Present full electronic search strategy for at least one database, including any limits used, such that it could be repeated.

9 State the process for selecting studies (i.e., screening, eligibility, included in systematic review, and, if applicable, included in the meta-analysis).

10 Describe method of data extraction from reports (e.g., piloted forms, independently, in duplicate) and any processes for obtaining and confirming data from investigators.

11 List and define all variables for which data were sought (e.g., PICOS, funding sources) and any assumptions and simplifications made.

12 Describe methods used for assessing risk of bias of individual studies (including specification of whether this was done at the study or outcome level), and how this information is to be used in any data synthesis.

13 State the principal summary measures (e.g., risk ratio, difference in means).

14 Describe the methods of handling data and combining results of studies, if done, including measures of consistency (e.g., I²) for each meta-analysis.
$1-2$

1

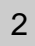

Appendix 3

3

3

Appendix 2

3

Figure 1

3-4

Appendix 2

PROBAST and QUIPS tool

3

Difference in means

Not done due to

Heterogeneity in studies 


\section{PRRISMA Checklist}

19

zsection/topic

21

2 fisk of bias across

2şudies

24

2f5odditional analyses

26

2ु్ESULTS

2Study selection

30

31

38udy characteristics

33

34

अ jsk of bias within

3ъtudies

3esults of individual

3\%qudies

39

48ynthesis of results

41 P.jk of bias across

43 ţudies

4 Additional analysis

45

\section{GiSCUSSION}

48ummary of

4eqiidence

50

5-1mitations

52

54 ponclusions

55

5 שUNDING

57

5 funding

59

60

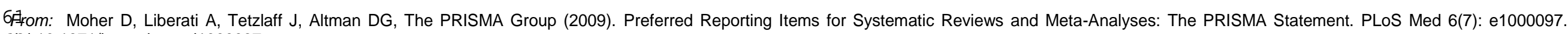
$60 \mathrm{i}: 10.1371 /$ journal.pmed1000097
\# Checklist item

15 Specify any assessment of risk of bias that may affect the cumulative evidence (e.g., publication bias, selective reporting within studies)

16 Describe methods of additional analyses (e.g., sensitivity or subgroup analyses, meta-regression), if done, indicating which were pre-specified.

17 Give numbers of studies screened, assessed for eligibility, and included in the review, with reasons for exclusions at each stage, ideally with a flow diagram.

18 For each study, present characteristics for which data were extracted (e.g., study size, PICOS, follow-up period) and provide the citations.

19 Present data on risk of bias of each study and, if available, any outcome level assessment (see item 12).

20 For all outcomes considered (benefits or harms), present, for each study: (a) simple summary data for each intervention group (b) effect estimates and confidence intervals, ideally with a forest plot.

21 Present results of each meta-analysis done, including confidence intervals and measures of consistency.

22 Present results of any assessment of risk of bias across studies (see Item 15).

23 Give results of additional analyses, if done (e.g., sensitivity or subgroup analyses, meta-regression [see Item 16]).

24 Summarize the main findings including the strength of evidence for each main outcome; consider their relevance to key groups (e.g., healthcare providers, users, and policy makers).

25 Discuss limitations at study and outcome level (e.g., risk of bias), and at review-level (e.g., incomplete retrieval of identified research, reporting bias).

26 Provide a general interpretation of the results in the context of other evidence, and implications for future research.

27 Describe sources of funding for the systematic review and other support (e.g., supply of data); role of funders for the systematic review.

\section{Reported on page \#}

Selection bias- procedure subgroups

Not done

Figure 1

Table 1

Table 2

Not done

Not done

Table 2

Not done

11-14

15

16

Title page

63 


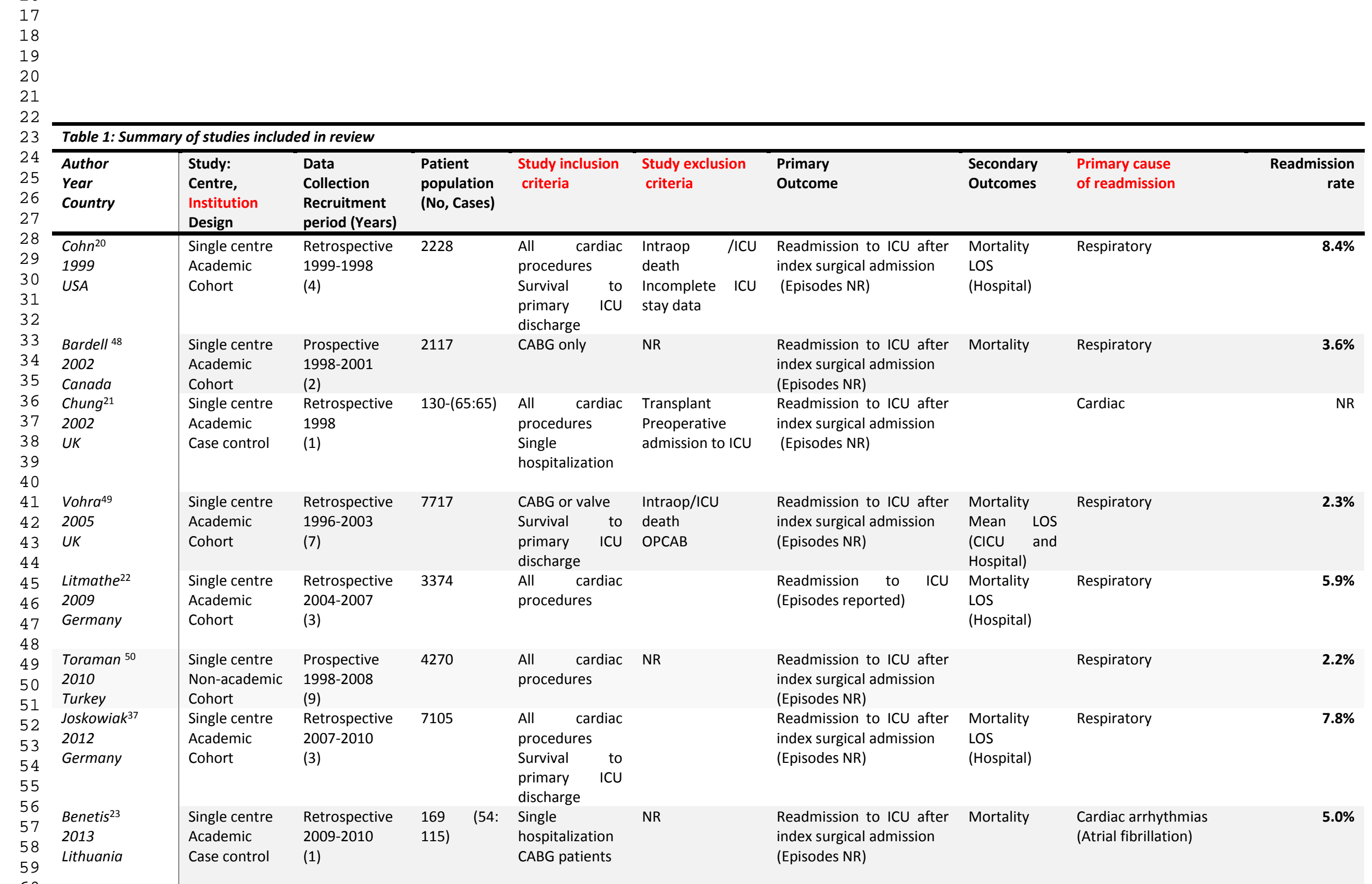




\section{Single centre} Academic

Cohort

Single centre

Academic

Cohort

\section{Giakoumidakis 51}

2014

Greece

Gumus ${ }^{36}$

2014

Turkey

Jarzabek $^{24}$

2014

Poland

\section{Single centre} Academic

Cohort

Single centre

Academic

Cohort

Single centre

NR

Case control

Single centre

Academic

Cohort

Single centre

Academic

Cohort

Single centre

Academic

Cohort

Single centre

Academic
Retrospective 2005-2010

(5)

Prospective

2004-2012

(8)

Retrospective 2011-2012

(1)

\section{Retrospective} 2010-2013

\section{(3)}

Retrospective 2008-2010

(2.7)

2076

(56:2020)$$
\text { . }
$$

(56:2020)

\section{All cardiac Aortic aneurysm, \\ Survival to dissection, primary ICU Cardiac discharge \\ aneurysm, Other \\ rate diseases of health and great vessels}

All cardiac Heart transplant procedures

Survival to
primary ICU

discharge

Retrospective 2013-2014

(2)

2009-2013

Prospective

2013-2014

(1)

Retrospective 2012-2013
1167

\section{All cardiac NR} procedures

532

CABG

1368 VAD
Readmission to ICU after Subgroup index surgical admission analysis

(Episodes reported)

Readmission to ICU after Mortality

index surgical admission LOS

(Episodes reported) (Hospital)

Readmission to ICU after Mortality index surgical admission

due to cause directly

related to primary

admission to ICU

Readmission to ICU after Mortality

index surgical admission

(Episodes NR)

Readmission to ICU after Mortality

index surgical admission LOS

(Episodes NR)

Readmission to ICU after Mortality

index surgical admission LOS

due to cause directly (Hospital)

related to

mission to ICU

(Episodes reported)

$\begin{array}{lll}\text { Readmission to ICU after Mortality NR } & 4.5 \%\end{array}$

index surgical admission

(Episodes reported)

Incomplete ICU Readmission to ICU after Mortality Respiratory

(Episodes

reported)

All cardiac Planned Readmission to ICU after Mortality Cardiac
(Hospital)

Haemodynamic

instability

Respiratory

primary

On-pump $4.4 \%$

OPCAB $4.0 \%$

$4.4 \%$

$5.3 \%$

$2.7 \%$

$1.8 \%$

\section{$\%$}

realision


Roumani42

\section{8}

USA

$\mathrm{Hui}^{18}$

2018

USA

$L i^{33}$

2019

China

Verma 29

2019

Canada

Single centre

(1)

Retrospective

2004-2012

Case control

Single centre

(9)

Academic

Retrospective

2009-2016

Cohort

(7)

Single centre Retrospective

Academic

Cohort

Single centre

Academic

NR

Cohort

Retrospective

2007-2015

Single centre

(8)

Academic

2016-2017

Cohort

(1)

Single centre

Retrospective

Academic

2015-2016

Cohort

(1)

Single centre

Academic

Retrospective

1194

2001

Italy

Kogan $^{19}$

2003

Cohort

\section{(3)}

Single centre Retrospective

Academic

NR

Israel

Cohort

(2.25)

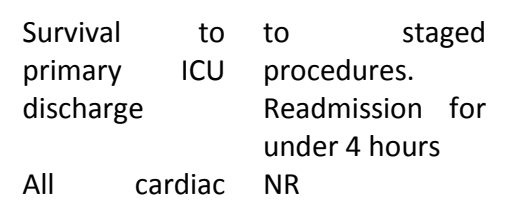

Readmission to ICU after Mortality

index surgical admission

All cardiac Readmission to Readmission to ICU after Mortality procedures

ICU from home

index surgical admission

(Episodes reported)

All cardiac Readmission to Readmission to ICU after NR

procedures ICU from home index surgical admission

(Episodes NR)

Primary LVAD $\quad<18$ years Readmission to ICU after

Survival to LVAD exchange index surgical admission

primary ICU Admitted by (Episodes NR)

discharge study end-date

Valve surgery Congenital

Survival to valvular disease

Readmission to ICU after Mortality

index surgical admission LOS

primary ICU Incomplete ICU (Episodes reported) (Hospital)

discharge stay data

CABG, Valve or Non-

Readmission to ICU after Mortality

index surgical admission LOS

combined cardiovascular

(Episodes reported)

(Hospital)

to procedures,

primary ICU Transplant, VAD

discharge or ECMO

First insertion

readmission

episode

CABG

Survival to

primary ICU

discharge

All cardiac Transplant,

procedures

Aortic aneurysm

and dissection

repair

Readmission to ICU after

Mortality

LOS

(Episodes NR)

(Hospital)

Readmission to ICU after Mortality

index surgical admission LOS

(Episodes NR, Timing (Hospital) reported)
Cardiopulmonary

instability

and

respiratory failure

Massive bleeding

$3.5 \%$

$3.2 \%$

NR

$8.1 \%$

Bleeding

(Haemothorax

tamponade)

Cardiac

$13.4 \%$

NR

$4.6 \%$

Bleeding

Overall 1.3\%

D0-1.1\%,

D1-1.0\%

Respiratory

D2-11.5\%

Readmission

$3.2 \%$

$<24 \mathrm{~h}-$

$47.5 \%$

24-48h- $28.3 \%$

$>48 \mathrm{~h}-24.5 \%$ 


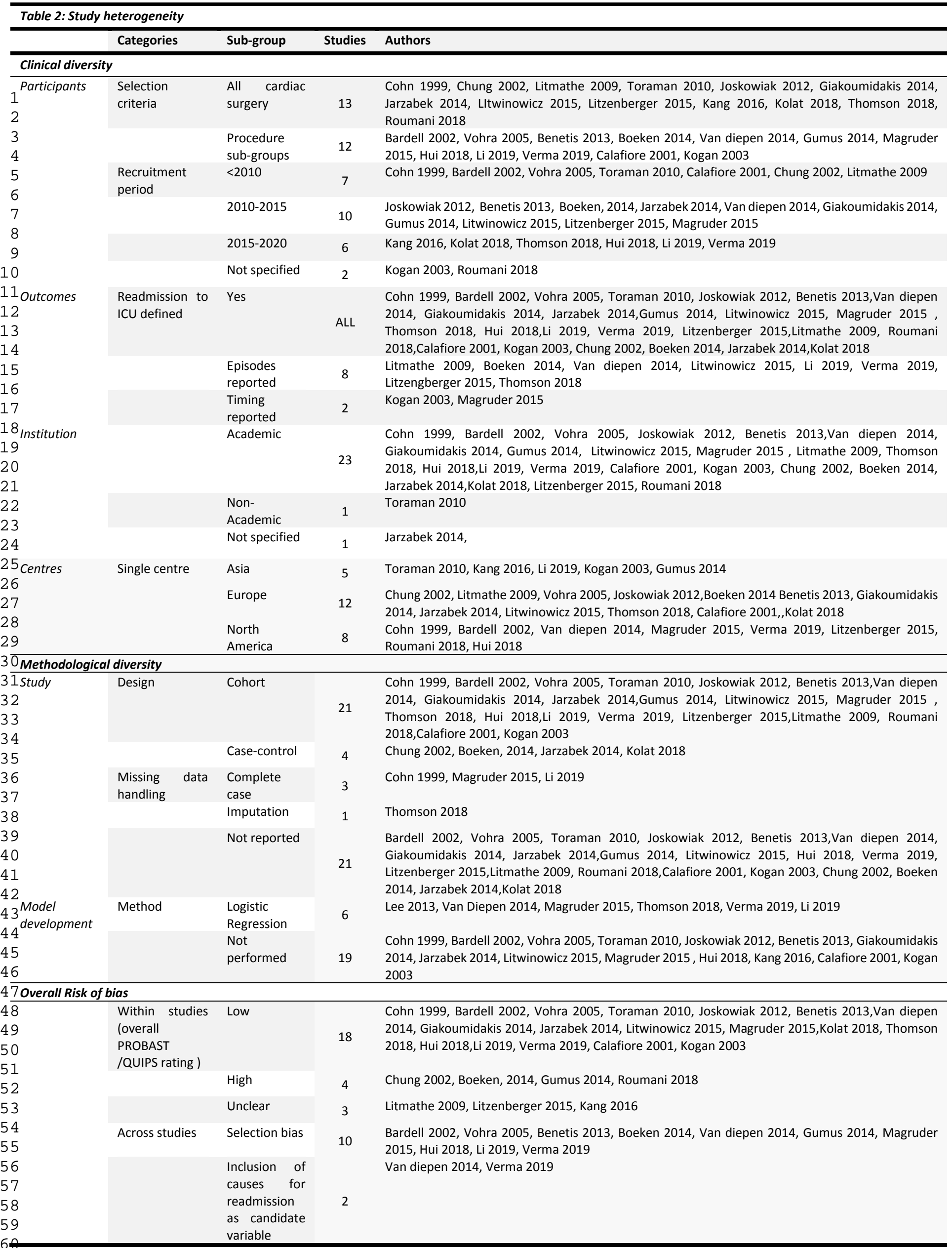




\begin{tabular}{|c|c|c|c|c|c|c|c|c|c|c|c|}
\hline \multirow[t]{2}{*}{ Model } & \multirow[t]{2}{*}{ Author } & \multirow{2}{*}{$\begin{array}{l}\text { Predictor } \\
\text { selection } \\
\text { univariate } \\
(p \text { value }<0.05 \text { ) }\end{array}$} & \multirow{2}{*}{$\begin{array}{l}\text { Validation } \\
\text { technique }\end{array}$} & \multicolumn{4}{|c|}{ Development } & \multicolumn{4}{|c|}{ Validation } \\
\hline & & & & Cohort (n) & $\begin{array}{l}\text { Events per } \\
\text { variable }\end{array}$ & $\begin{array}{l}\text { Measure of } \\
\text { Calibration }\end{array}$ & $\begin{array}{l}\text { Measure of } \\
\text { Discrimination }\end{array}$ & Cohort (n) & $\begin{array}{l}\text { Events per } \\
\text { variable }\end{array}$ & $\begin{array}{l}\text { Measure of } \\
\text { Calibration }\end{array}$ & $\begin{array}{l}\text { Measure of } \\
\text { Discrimination }\end{array}$ \\
\hline BATS model & $\begin{array}{l}\text { Magruder } \\
\text { USA } \\
2015\end{array}$ & $\begin{array}{l}\text { Akaike } \\
\text { Information } \\
\text { Criterion }\end{array}$ & NR & $\begin{array}{l}\text { Prospective } \\
\text { CABG or AVR } \\
\text { (421) }\end{array}$ & $\begin{array}{l}3.1 \\
(31 / 10)\end{array}$ & $R^{2}=0.86$ & $\mathrm{AUC}=0.81$ & NR & NR & NR & NR \\
\hline \multirow[t]{2}{*}{$\begin{array}{l}\text { APPROACH } \\
\text { model }\end{array}$} & $\begin{array}{l}\text { Van Diepen } \\
\text { Canada } \\
2014\end{array}$ & $\begin{array}{l}\text { Forward } \\
\text { stepwise }\end{array}$ & $\begin{array}{l}\text { Internal } \\
\text { Bootstrap } \\
\text { (1000 rep) }\end{array}$ & $\begin{array}{l}\text { Prospective } \\
\text { CABG or Valvular } \\
\text { (10799) }\end{array}$ & $\begin{array}{l}40 \\
(479 / 12)\end{array}$ & $\begin{array}{l}\mathrm{HL} \\
\text { chi-square } \\
p=0.19\end{array}$ & $A \cup C=0.80$ & $\begin{array}{l}\text { Prospective } \\
\text { CABG or Valvular } \\
\text { (10799) }\end{array}$ & $\begin{array}{l}40 \\
(479 / 12)\end{array}$ & NR & NR \\
\hline & $\begin{array}{l}\text { Verma } \\
\text { Canada } \\
2019\end{array}$ & $\begin{array}{l}\text { Forward } \\
\text { stepwise }\end{array}$ & $\begin{array}{l}\text { Internal } \\
\text { Bootstrap } \\
\text { (1000 rep) }\end{array}$ & NR & NR & NR & NR & $\begin{array}{l}\text { Prospective CABG } \\
\text { Or Valvular } \\
(805)\end{array}$ & $\begin{array}{l}1.9 \\
(37 / 19)\end{array}$ & $\begin{array}{l}\mathrm{HL} \\
\text { chi-square } \\
\mathrm{p}=0.01\end{array}$ & $\mathrm{AUC}=0.75$ \\
\hline $\begin{array}{l}\text { APPROACH } \\
\text { model } \\
\text { refined }\end{array}$ & $\begin{array}{l}\text { Verma } \\
\text { Canada } \\
2019\end{array}$ & $\begin{array}{l}\text { Forward } \\
\text { stepwise }\end{array}$ & NR & $\begin{array}{l}\text { Prospective CABG } \\
\text { Or Valvular } \\
(805)\end{array}$ & $\begin{array}{l}1.85 \\
(37 / 20)\end{array}$ & $\begin{array}{l}\mathrm{HL} \\
\text { chi-square } \\
p=0.75\end{array}$ & $A \cup C=0.78$ & NR & NR & NR & NR \\
\hline Thomson & $\begin{array}{l}\text { Thomson } \\
\text { UK } \\
2018\end{array}$ & $\begin{array}{l}\text { Backward } \\
\text { stepwise }\end{array}$ & $\begin{array}{l}\text { Internal } \\
\text { Bootstrap } \\
\text { (2000 rep) }\end{array}$ & $\begin{array}{l}\text { Retrospective } \\
\text { Mixed Cardiac } \\
\text { (4869) }\end{array}$ & $\begin{array}{l}17.3 \\
(56 / 9)\end{array}$ & $\begin{array}{l}\text { Good } \\
\text { correlation }\end{array}$ & $\begin{array}{l}\text { Good } \\
\text { discrimination }\end{array}$ & $\begin{array}{l}\text { Retrospective } \\
\text { Mixed Cardiac } \\
\text { (4869) }\end{array}$ & $\begin{array}{l}17.3 \\
(56 / 9)\end{array}$ & NR & NR \\
\hline $\mathrm{Li}$ & $\begin{array}{l}\text { Li } \\
\text { China } \\
2019\end{array}$ & $\begin{array}{l}\text { Forward } \\
\text { stepwise }\end{array}$ & $\begin{array}{l}\text { Temporal } \\
\text { Split } \\
\text { sample }\end{array}$ & $\begin{array}{l}\text { Retrospective } \\
\text { Valve surgery } \\
(824)\end{array}$ & $\begin{array}{l}4 \\
(52 / 13)\end{array}$ & $\begin{array}{l}\mathrm{HL} \\
\text { chi-square } \\
\mathrm{p}=0.30\end{array}$ & $A \cup C=0.89$ & $\begin{array}{l}\text { Retrospective } \\
\text { Valve surgery } \\
\text { (392) }\end{array}$ & $\begin{array}{l}2 \\
(28 / 13)\end{array}$ & $\begin{array}{l}\mathrm{HL} \\
\text { chi-square } \\
\mathrm{p}=0.29\end{array}$ & $A \cup C=0.88$ \\
\hline
\end{tabular}

Abbreviations: rep-replications, NR-Not Reported, AUC-Area Under Curve, HL-Hosmer-Lemenshow 
Figure 1: Study selection flow diagram
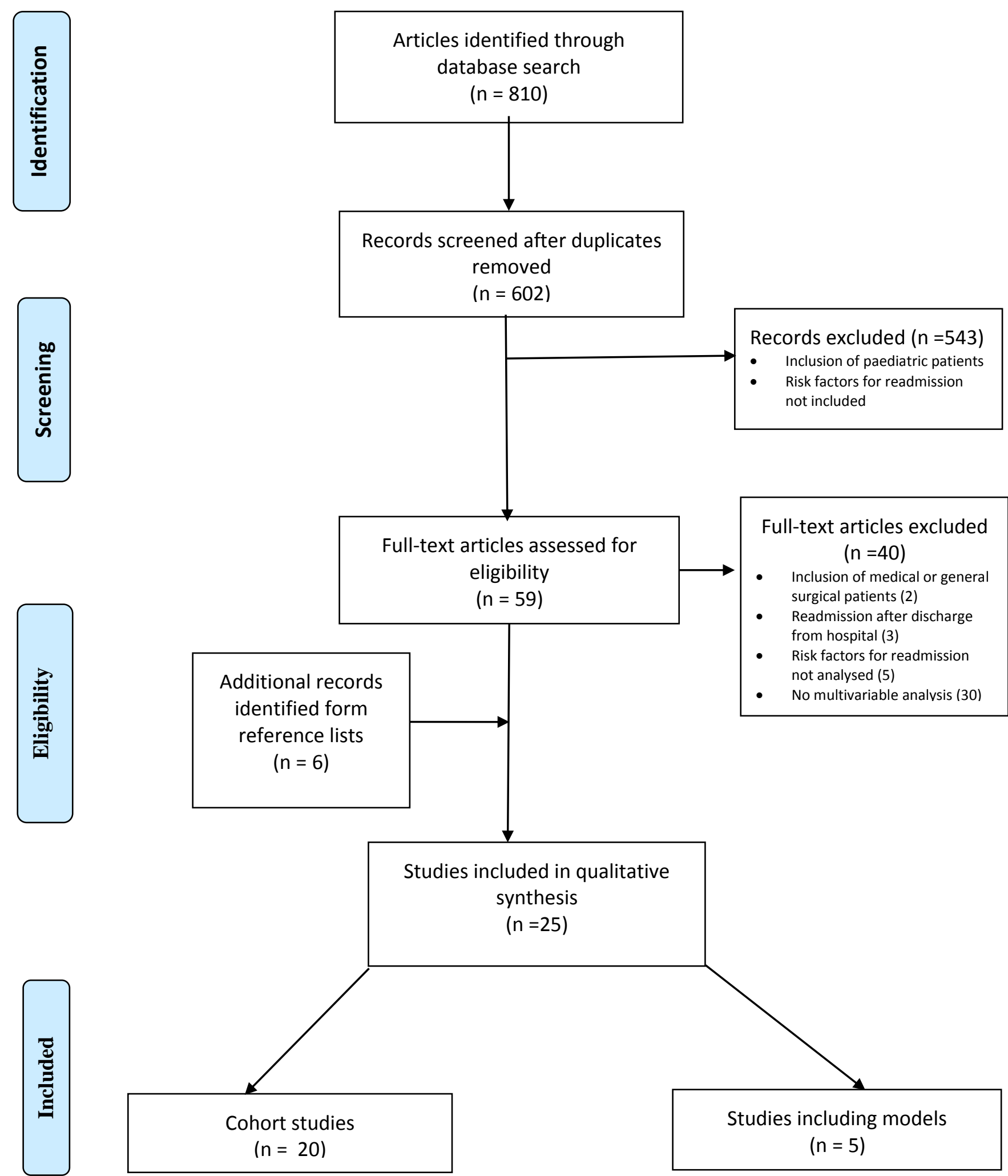
Figure 2: Median percentage of readmissions due to specific causes (when specified) across included studies

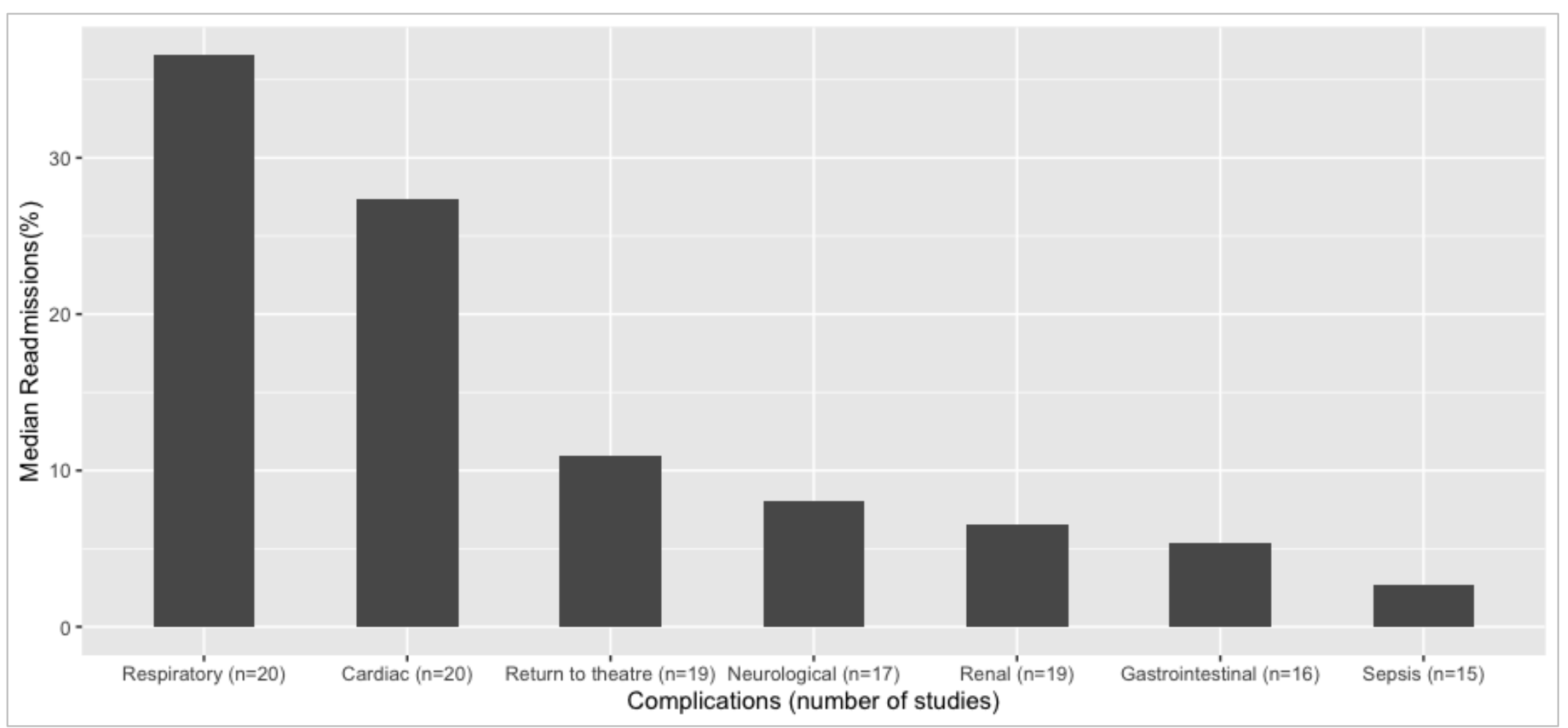




\section{Figure 3: Number of studies identifying specific risk factors readmission to $\mathrm{CICU}$ on multivariable analysis}

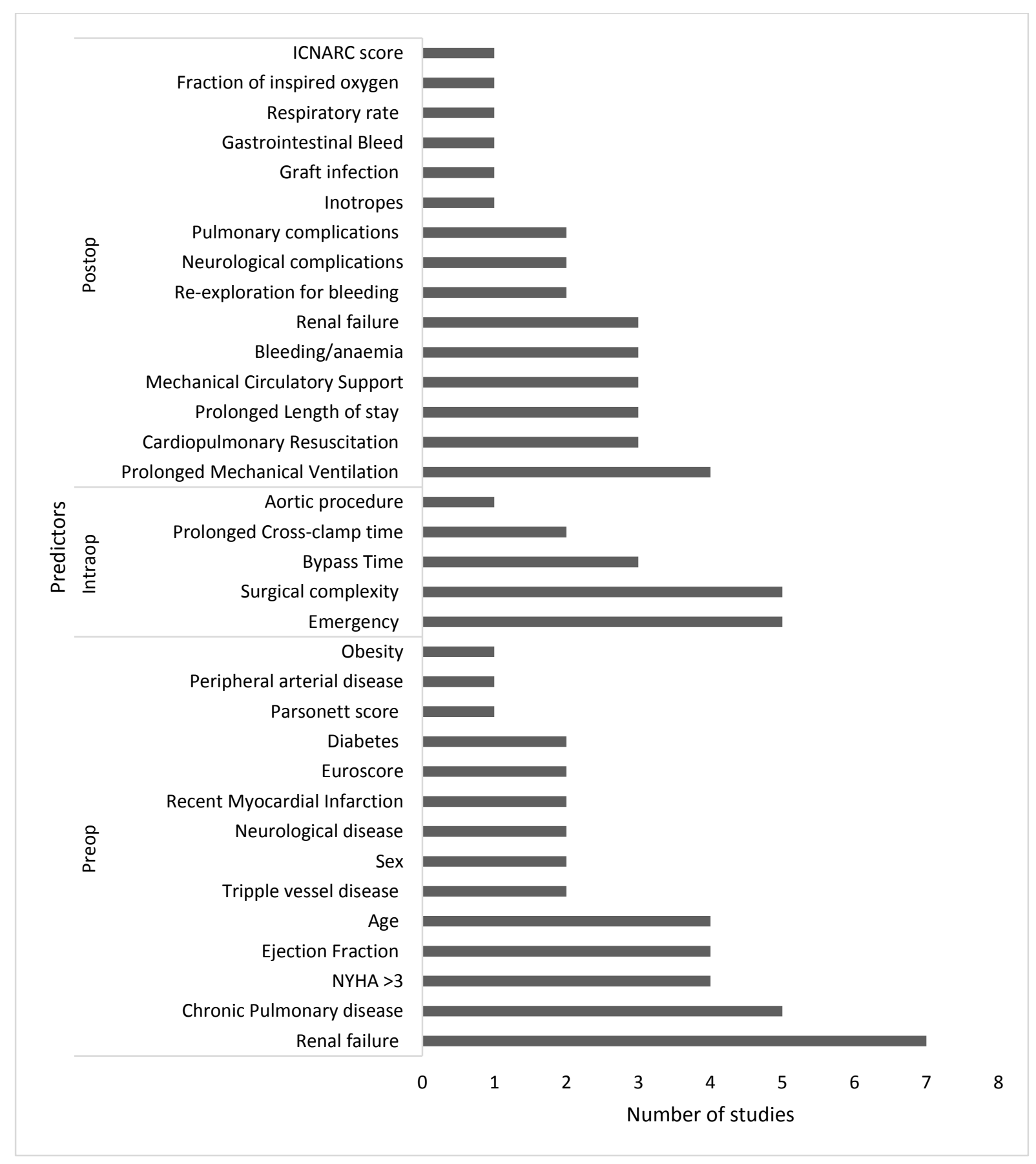

Figure 3:Abbreviations; ICNARC-Intensive care national audit and research centre, NYHA-New York Heart Association 